\title{
Comparative Study on Surfactants Mixtures in Aqueous Solution at Atmospheric Pressure and 10 bar Reservoir Atmosphere
}

\author{
Andrea Elekes ${ }^{1 *}$, Roland Nagy¹, László Bartha², Árpád Vágó3 \\ ${ }^{1}$ Department of MOL Department of Hydrocarbon and Coal Processing, Faculty of Engineering, University of Pannonia, \\ H-8200 Veszprém, Egyetem str. 10., Hungary \\ 2 Department of Department of Chemical Engineering Science, Faculty of Engineering, University of Pannonia, \\ H-8200 Veszprém, Egyetem str. 10., Hungary \\ ${ }^{3}$ MOL Plc., Research \& Development Division, H-1117 Budapest, Október huszonharmadika str. 18, Hungary \\ ${ }^{*}$ Corresponding author, e-mail: elekesa@almos.uni-pannon.hu
}

Received: 03 April 2018, Accepted: 21 August 2018, Published online: 12 November 2018

\begin{abstract}
This paper considers anionic and nonionic surfactants, as candidates for crude oil production by enhancement applications. In this study some colloidal properties of surfactants were tested by conventional and new test methods. The oil in water type emulsions have great importance in the petroleum industry. The stability of crude oil in water emulsions are investigated in a wide range of physical and chemical circumstances. Investigations at 10 bar are needed to get knowledges on the real conditions of the given petroleum exploration processes. A special glass cell was used for the tests of the mixtures various crude oil-water emulsions under hydrocarbon gas atmosphere and for the oil disclapement efficiency. Based on the experimental results it was found that emulsifying capacity was changed significantly by the real process conditions. The decrease of the density of hydrocarbon phase was contributed to the overall reduction in the efficiency of emulsifiers also occurred. Based on the experimented data it is supported to pay more attention to apply the real test conditions or approximate the real values.
\end{abstract}

Keywords

atmospheric pressure and 10 bar, crude oil, surfactant, emulsifying capacity, oil displacement efficiency

\section{Introduction}

Crude oil is one of the most actively traded commodities in the world. Worldwide demand for crude oil has been steadily intensifying over the past 20 years, as world demand for crude has grown from 60 to 84 million barrels per day [1, 2].

In parallel with the rapid growth of energy demand the quantity of economically exploitable crude oil is continuously decreasing [3]. In order to further improve of the oil recovery efficiency the chemical enhanced oil recovery methods were developed [4].

Our research was dealt with the examination of emulsions which may occur during enhancement of petroleum exploitation $[5,6]$. In this process, the aqueous solution and the crude oil mixture get various stable emulsions.

The oil in water type emulsions have great importance in the petroleum industry. The emulsification behavior of a crude oil-water system is greatly depends on the compositions of a crude oil [7].
The formation of emulsions is common during the production and transportation process of crude oil, which can greatly affect the flow characteristics of multiphase flow $[2,8-10]$. We published our first part of the work on the emulsification behaviors of crude-oil-water system.

The natural surfactants in the crude oil, such as asphaltenes, resins, and acidic compounds etc., reducing the interfacial tension of oil-water and forming an interfacial film with certain mechanical strength, that plays a key role in the emulsion formation and stabilization. Therefore, the differences in compositions of crude oils may result in large difference in the emulsification behaviors [11].

The environmentally friendly and bio-degradable vegetable oil based nonionic surfactants are used in the petroleum and petrochemical industry in many areas. The investigations under high-pressure can provide useful 
information many industrial applications of surfactants implemented into the petroleum processing [12].

In this study the emulsion stability of the crude oil-water type emulsions were investigated both at the atmospheric and relatively high (10 bar) pressure conditions. Our aim is to present a test method to better approximate the actual conditions in the oil storage tank. The complex selection method of the surfactants can be supported by the described method. In addition, we investigate that, in the case of two different types of crude oil, the relationship between the emulsifying capacity and the oil displacement effect of each of the surfactant compositions.

\section{Materials}

For the preparation of emulsions the commercial surfactants (SPAN and LES marked) were used.

The nonionic surfactants type materials were technical grades of sorbitan monolaurate, monopalmitate, monostearate and mono-oleate, respectively, Span 20, 40, 60 and 80 used as received.

The sodium lauryl ether sulfate (LES) is an important anionic surfactant used generally in many household and personal care products.

The composition of the surfactant mixtures used for the experiments were $50 \mathrm{w} / \mathrm{w} \%$ nonionic and $50 \mathrm{w} / \mathrm{w} \%$ anionic surfactant all mixtures.

The surfactant mixtures were marked with $\mathrm{M}-1, \mathrm{M}-2$, M-3 and M-4.

\subsection{Preparation of model brine}

The synthetic brine was prepared, which contained 0.5 $\mathrm{g} / 1 \mathrm{NaCl}, 0.2 \mathrm{~g} / 1 \mathrm{CaCl}_{2} \cdot 2 \mathrm{H}_{2} \mathrm{O}, 2.6 \mathrm{~g} / 1 \mathrm{NaHCO}_{3}$ and $2.6 \mathrm{~g} / 1$ $\mathrm{CH}_{3} \mathrm{COONa} \cdot 2 \mathrm{H}_{2} \mathrm{O}$. There salts were dissolved in distilled water for the preparation of model brine [13].

\subsection{Preparation of the model hydrocarbon mixture}

Exactly $60 \mathrm{~cm}^{3}$ of n-heptane was mixed with $40 \mathrm{~cm}^{3}$ of toluene in a $250 \mathrm{~cm}^{3}$ conical flask. Before mixing, $0.1 \mathrm{~g}$ of $50 / 70$ penetration grade bitumen was dissolved in $40 \mathrm{~cm} 3$ toluene. To prepare $0.05 \%$ concentration of bitumen, 0.05 $\mathrm{g}$ of bitumen was dissolved in $40 \mathrm{~cm}^{3}$ of toluene and was made up to $100 \mathrm{~cm}^{3}$ with heptane, since bitumen are soluble in toluene [14].

\subsection{Crude oil}

The tests were performed with Hungarian paraffinic type crude oil and brine to compare model and real conditions. Anionic and non-ionic surfactants were used to reduce oil-water interfacial tension. The main properties of crude oil from South-East Hungary and model hydrocarbon mixture (model oil) were used as shown in Table 1.

\subsection{Preparation of emulsions}

Crude oil emulsions were prepared by dispersing $10 \mathrm{~cm}^{3}$ of model brine in $10 \mathrm{~cm}^{3}$ model hydrocarbon mixture or crude oil sample by using a mechanical shaker at speed of $500 \mathrm{rpm}$ for $10 \mathrm{~min}$. The emulsion portion was dispensed into a $20 \mathrm{~cm}^{3}$ measuring cylinder and its volume was recorded. Also the separation of the emulsion was also monitored at different time interval to determine the stability of the emulsion.

\section{Methods}

\subsection{Investigation of emulsifying capacity on high pressure}

The scheme of the special glass cell produced for the tests of the mixtures various crude oil-water emulsions under hydrocarbon gas atmosphere is shown in the Fig. 1. The high-pressure glass cell was used for simulation of the crude oil-water type emulsion storage in hydrocarbon atmosphere.

Table 2 shows the composition of the reservoir gas used for the stability test of emulsions.

Table 1 Properties of crude oil and model oil

\begin{tabular}{lcc}
\hline Properties & Crude oil & Model oil \\
\hline Density, g/cm ${ }^{3}\left(20^{\circ} \mathrm{C}\right)$ & 0.830 & 0.760 \\
Dynamic viscosity, mPa.s $\left(20^{\circ} \mathrm{C}\right)$ & 14.6 & 0.53 \\
Acid number, mg KOH/g & 0.91 & 0.47 \\
Watson characterization factor & 13.2 & 11.5 \\
Character of crude oil & Paraffinic & Naphthenic \\
\hline
\end{tabular}

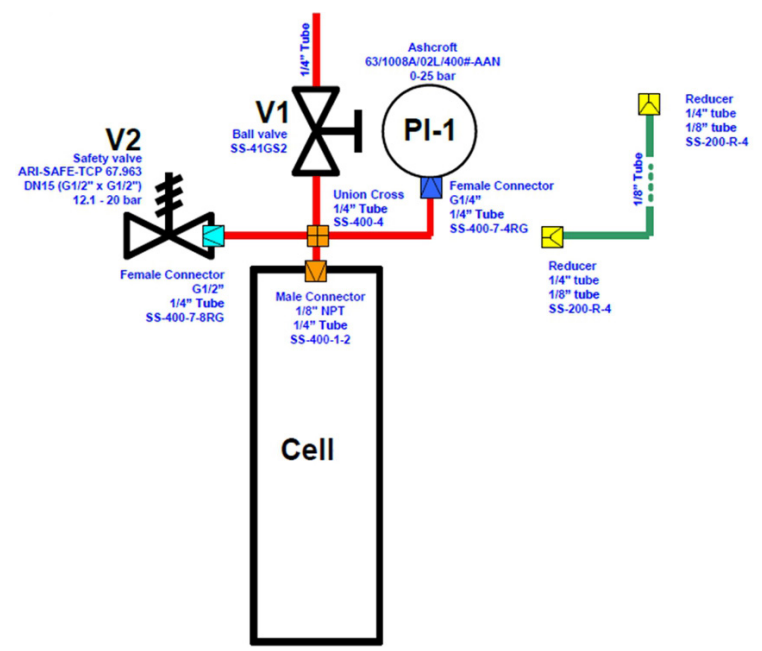

Fig. 1 High-pressure glass cell for testing of the phase stability of emulsions 
Table 2 Composition of the reservoir gas

\begin{tabular}{lc}
\hline Component & Concentration, v/v\%* \\
\hline Methane & 82.7 \\
Ethane & 9.1 \\
Propane & 5.1 \\
Butane & 3.1 \\
\hline *applied method: $G C$ &
\end{tabular}

\subsection{Determination of the emulsifying capacity}

The stability of emulsions was assessed by monitoring the increase with the storage time the position of clear water-emulsion interface. The emulsion was allowed to stand in $20 \mathrm{~cm}^{3}$ measuring cylinder that the volume of water and hydrocarbon phase separation was recorded to evaluate the stability of the emulsions [15].

\subsection{Oil displacement efficiency}

The practical determination of the surface activity method has not been reported in the specific publications, which could be the extent to porous surfaces characterized by washing efficiency of the oil. It was developed a method for oil flushing effect, that based on the foundations of thin layer chromatography of organic chemical analysis has been used.

The first step of the test procedure is the preparation of the thin layer. Then $4 \mu \mathrm{l}$ of crude oil should be spotted on the thin layer at $2 \mathrm{~cm}$ from the base of the glass slab. Then the sample should be run in the emulsifier mixture at $80^{\circ} \mathrm{C}$ for 3 hours. The oil displacement efficiency (ODE) of the surfactant composition can be evaluated by the distance from the centre of the oil spot to the upper edge of the spot measured in $\mathrm{mm}$. The maximum difference between the parallel results was in the interval of $\pm 10 \%$ [16].

\section{Results and discussion}

The emulsions were investigated according to the internal standard method and at atmospheric pressure. Furthermore the effects of emulsifiers were examined by influence of gas pressure from South-Hungary reservoir. The phase ratios of the resulting emulsions were read after one hour, 4 hours and after 24 hours at $80^{\circ} \mathrm{C}$.

The next step the phase ratios of the resulting emulsions were read after 1 hour, 4 hours and after 24 hours at $80{ }^{\circ} \mathrm{C}$.

Upper phase can contain crude oil or crude oil in the form of water in crude oil type emulsion (W/O). The middle phase can be crude oil in water emulsion (W/O). The preferred emulsion type of enhancement of petroleum exploitation is the crude oil in water emulsion.

\subsection{Atmospheric emulsifying capacity at $80^{\circ} \mathrm{C}$}

The Fig. 2 and Fig. 3 displays the phase separation of surfactant solution containing real crude oil-water type and model crude oil-water type emulsions.

Based on measurements it was found that there were different in the volume of emulsion phases when using model and real oil. The emulsions phases were more stable in the case of emulsions contained model crude oil than the real crude oil. It was found that the volumes of middle emulsion phases were decreased over time.

Mixture M-1. had the highest emulsifying capacity at atmospheric pressure. The largest middle phase (40 V/V\%) was in the sample M-1 from a model crude oil after 4 hours of storage.

Emulsions from real oil separated almost completely after 4 hours settling time.

\subsection{High pressure emulsifying capacity at 10 bar reservoir gas and $80^{\circ} \mathrm{C}$}

The high-pressure glass cell (Fig. 1) was used for simulation of the crude oil/water type emulsion storage in hydrocarbon atmosphere. Fig. 4 and Fig. 5 shows the

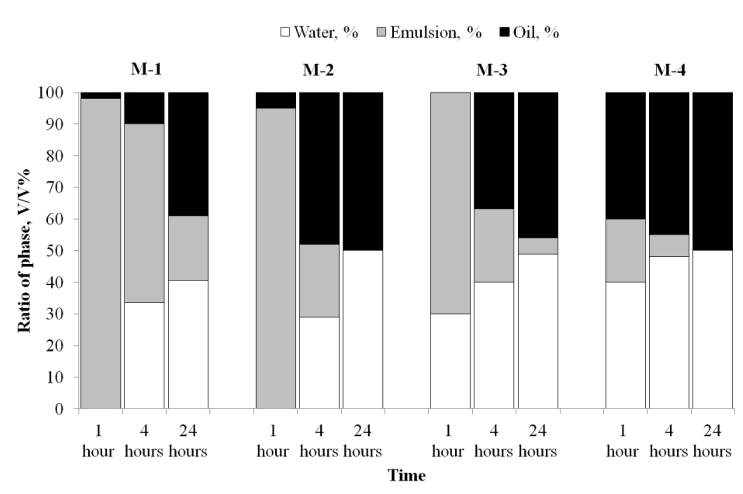

Fig. 2 Phase ratio of crude oil-water emulsions at $80^{\circ} \mathrm{C}$ and atmospheric pressure

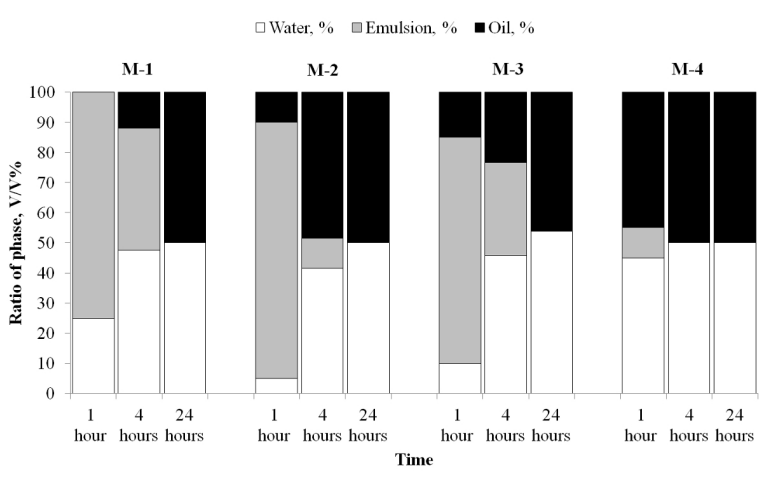

Fig. 3 Phase ratio of model oil-water emulsions at $80^{\circ} \mathrm{C}$ and atmospheric pressure 
phase separation of surfactant solution containing real crude oil-water and model crude oil-water emulsions at a pressure of 10 bar.

Based on the results of the emulsifying capacity tests at a pressure of 10 bar it was found that the sign M-1 and M-2 surfactant mixtures were the most effective for 24 hours. However the M-4 emulsion separated totally after 1 hour already.

The viscosity of emulsions changed due to reservoir gas dissolving therefore the value of the emulsifying capacity also changed. Since the stability of emulsions has improved, so there is no correlation between the results at the atmospheric and higher pressure.

However, correlation can be observed between emulsion stability and the surfactant sructure. Contrary to the literature, the mixture containing the shorter chain surfactant had an emulsifying effect better than that of the longer chain. This effect is due to the synergistic effect of the anionic and nonionic surfactants.

Overall we found higher amount of middle phases resulted by tests at higher pressure.

\subsection{Oil displacement efficiency}

Another important property of the surfactants is the detergency. Fig. 6 shows the oil displacement efficiency of surfactants in aqueous solution at atmospheric and 10 bar.

Fig. 7 shows the oil displacement efficiency of surfactant aqueous solution at model crude oil.

The oil displacement efficiency was different at different pressures and other crude oils.

The sign M-1 surfactant mixture was the most effective regarding the oil displacement efficiency both atmospheric and at 10 bar pressures.

In most cases it was found that the higher pressure and the lighter model oil is advantageous to removing crude oil from rock.

\section{Conclusion}

Emulsions were prepared by using synthetic and real brine, synthetic and real crude oil and surfactants and examined by atmospheric and 10 bar pressure conditions. It was found that emulsifying effect was changed significantly by the real conditions.

In the most cases it was observed that higher amount of middle phase related to the emulsifying capacity was resulted in the tests at higher pressures. Furthermore the higher pressure seemed to be advantageous to remove the crude oil from rock.

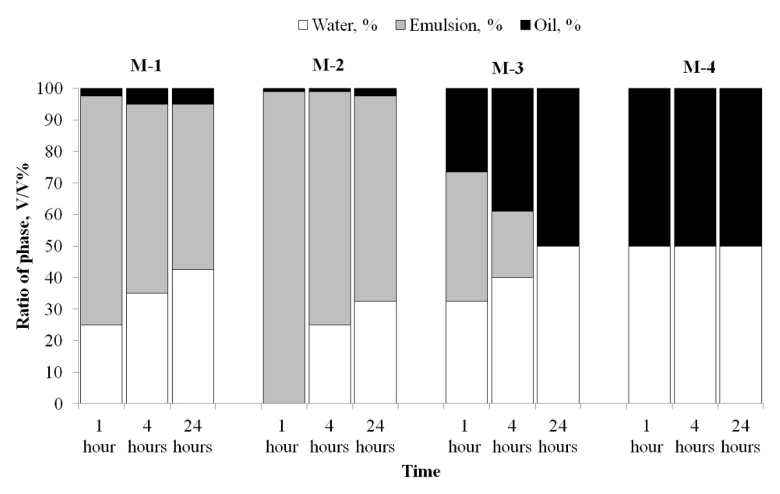

Fig. 4 Phase ratio of crude oil-water emulsions at $80^{\circ} \mathrm{C}$ and 10 bar

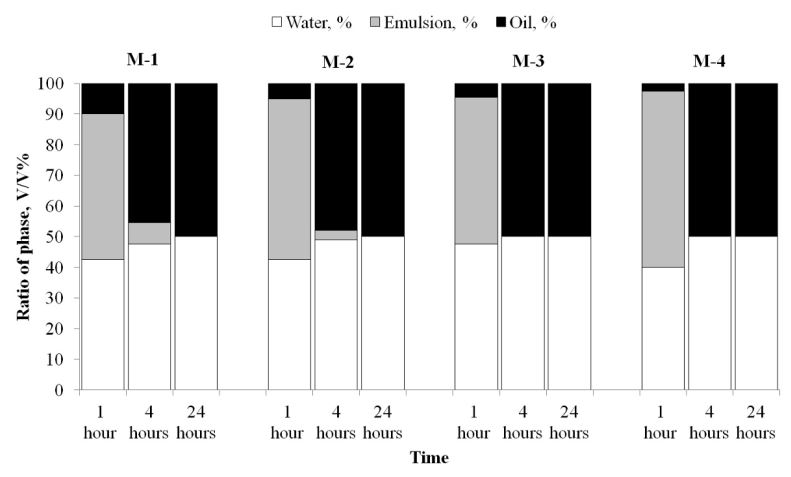

Fig. 5 Phase ratio of model oil-water emulsions at $80^{\circ} \mathrm{C}$ and 10 bar

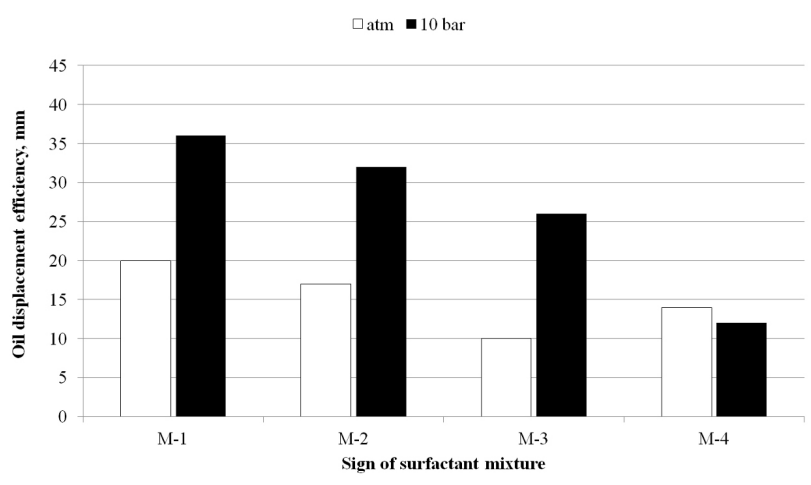

Fig. 6 Oil displacement efficiency of surfactant aqueous solution at $80^{\circ} \mathrm{C}$, atmospheric and at 10 bar (real crude oil)

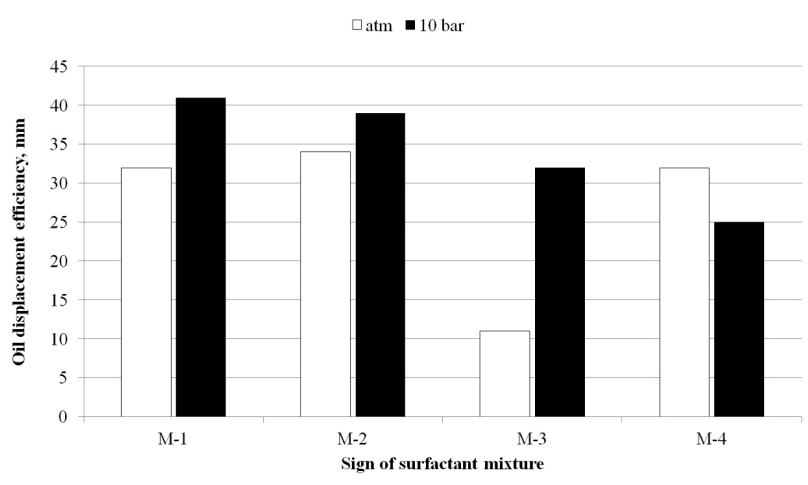

Fig. 7 Oil displacement efficiency of surfactant aqueous solution at $80^{\circ} \mathrm{C}$, atmospheric and at 10 bar (model crude oil) 
Among the tested surfactants mixtures containing SPAN-20 and SPAN-40 surfactants had the most stable emulsions and the best oil displacement efficiency. This effect is due to the synergistic effect of the anionic and nonionic surfactants.

\section{References}

[1] Hasan, S. W., Ghannam, M. T., Esmail, N. "Heavy crude oil viscosity reduction and rheology for pipeline transportation", Fuel, 89(5), pp. 1095-1100, 2010.

https://doi.org/10.1016/j.fuel.2009.12.021

[2] Hoshyargar, V., Ashrafizadeh, S. N. "Optimization of Flow Parameters of Heavy Crude Oil-in-Water Emulsions through Pipelines", Industrial \& Engineering Chemistry Research, 52(4), pp. 1600-1611, 2013.

https://oi.org/10.1021/ie302993m

[3] International Energy Agency "World energy outlook 2014", 2014, [online] Available at: https://www.iea.org/newsroom/news/2014/ november/world-energy-outlook-2014.html [Accessed: 26 January 2018]

[4] Lakatos, I., Lakatos-Szabó, J. "The significance of non-conventional hydrocarbons in the 21st century", Crude Oil and Natural Gas, 22, pp. 1-19, 2008.

[5] Lakatos, I., Lakatos-Szabó, J., Bódi, T., Vágó, Á., Szentes G. "Reservoir conformance enhancement in gas fields using microemulsions", Geosciences and Engineering, 1(1), pp. 187-204, 2012.

[6] Lakatos, I., Lakatos-Szabó, J., Szentes, G., Vadászi, M., Vágó, Á. "Novel Water Shutoff Treatments in Gas Wells Using Petroleum External Solutions and Microemulsions", presented at SPE European Formation Damage Conference \& Exhibition, Noordwijk, The Netherlands, June 2013. https://doi.org/10.2118/165175-MS

[7] Wen, J., Zhang, J., Wang, Z., Zhang, Y. "Correlations between emulsification behaviors of crude oil-water systems and crude oil compositions", Journal of Petroleum Science and Engineering, 146, pp. 1-9, 2016.

https://doi.org/10.1016/j.petrol.2016.04.010

[8] Plasencia, J., Pettersen, B., Nydal, O. J. "Pipe flow of water-incrude oil emulsions: Effective viscosity, inversion point and droplet size distribution", Journal of Petroleum Science and Engineering, 101, pp. 35-43, 2013.

https://doi.org/10.1016/j.petrol.2012.11.009
Because of the differences in the surfactant effects at high pressure it was suggested to supplement the complex selection system of the surfactants with the described method.

[9] Wang, W., Gong, J., Angeli, P. "Investigation on heavy crude-water two phase flow and related flow characteristics", International Journal of Multiphase Flow, 37(9), pp. 1156-1164, 2011. https://doi.org/10.1016/j.ijmultiphaseflow.2011.05.011

[10] Wen, J., Zhang, J., Wang, Z., Zhang, Z., Zheng, F., Zhu, Y., Han, S. "Full and Partial Emulsification of Crude Oil-Water Systems as a Function of Shear Intensity, Water Fraction, and Temperature", Industrial \& Engineering Chemistry Research, 53(22), pp. 9513-9520, 2014. https://doi.org/10.1021/ie501185s

[11] Kilpatrick, P. K. "Water-in-Crude Oil Emulsion Stabilization: Review and Unanswered Questions", Energy \& Fuels, 26(7), pp. 4017-4026, 2012. https://doi.org/10.1021/ef3003262

[12] Schramm, L. L. "Surfactants: Fundamentals and Applications in the Petroleum Industry", 1st ed., Cambridge University Press, Cambridge, UK, 2000.

[13] Yildiz, H. O., Valat, M., Morrow, N. R. "Effect of Brine Composition On Wettability And Oil Recovery of a Prudhoe Bay Crude Oil", Journal of Canadian Petroleum Technology, 38(1), 1999.

https://doi.org/10.2118/99-01-02

[14] Alimi, O. L., Oyedeji, O. F. "Stabilization of Model Crude Oil Emulsion using Different Concentrations of Asphaltene", ChemSearch Journal, 6(2), pp. 25-31, 2015.

https://doi.org/10.4314/csj.v6i2.5

[15] Peña, A. A., Hirasaki, G. J., Miller, C. A. "Chemically Induced Destabilization of Water-in-Crude Oil Emulsions", Industrial \& Engineering Chemistry Research, 44(5), pp. 11139-1149, 2005. https://doi.org/10.1021/ie049666i

[16] Nagy, R., Sallai, R., Bartha, L., Vágó, Á. "Selection Method of Surfactants for Chemical Enhanced Oil Recovery", Advances in Chemical Engineering and Science, 5(2), pp. 121-128, 2015. https://doi.org/10.4236/aces.2015.52013 